\title{
Endometrioma of the Abdominal Wall after Caesarean Section
}

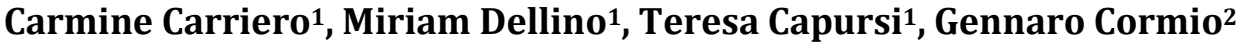 \\ ${ }^{1}$ Department of Interdisciplinary Medicine, Section of Gynecology and Obstetrics, University of Bari, Apulia, Italy \\ ${ }^{2}$ Department of Biomedical Sciences and Human Oncology, University of Bari, Apulia, Italy \\ Email: carmine.carriero@uniba.it
}

How to cite this paper: Carriero, C., Dellino, M., Capursi, T. and Cormio, G. (2017) Endometrioma of the Abdominal Wall after Caesarean Section. Open Journal of Obstetrics and Gynecology, 7, 907-914. https://doi.org/10.4236/ojog.2017.78091

Received: July 3, 2017

Accepted: August 13, 2017

Published: August 16, 2017

Copyright (c) 2017 by authors and Scientific Research Publishing Inc. This work is licensed under the Creative Commons Attribution International License (CC BY 4.0).

http://creativecommons.org/licenses/by/4.0/

Open Access

\begin{abstract}
Background: Endometrial cell implantation after abdominal surgery, mainly after caesarean section, may result in formation of endometrioma, which is usually described to be of various sizes, and adjacent to the surgical scar. Case: A 36-year old woman complaining of a mass of the abdominal wall with pain during the menstrual period, with a caesarean section 5 years earlier, presented a rounded tumour not contiguous to the Pfannenstiel's laparotomy scar, of hard consistence, fixed and adherent to the deep abdominal wall structures, located on the left paramedian epigastric region. Magnetic Resonance imaging showed the nodule, involving the deep layers of the abdominal wall and the distance from the laparotomic scar. Surgical removal was performed with wide excision of the lesion, causing a large wall defect. After histological confirmation (endometriosis) by frozen section, reconstruction of the abdominal wall required prolene mesh grafting. After twelve months the patient is healthy. Conclusion: When abdominal wall endometrioma is located distant from the scar, perhaps more frequently after Pfannenstiel's laparotomic incision, the differential diagnosis may be more difficult and MRI can help differentiating many of these lesions, and histological confirmation should be obtained intraoperatively, by frozen section, to allow an oncological resection if required.
\end{abstract}

\section{Keywords}

Abdominal Wall, Endometrioma, Endometriosis, Scar Endometrioma, Surgery

\section{Introduction}

Endometrial cell implantation after abdominal surgery, mainly after Caesarean Section, may result in formation of endometrioma, which is described to be of 
various sizes, and adjacent to the surgical scar. An unusual presentation of a large abdominal wall endometrioma, located at some distances from the scar of the previous caesarean section, is reported, and diagnostic and therapeutic approach is described.

\section{Case Report}

A 36-year-old woman was admitted to our hospital complaining of a mass of the abdominal wall with pain during the menstrual period. The mass was referred to have grown gradually in the past 2 years, with worsening of the intermittent and sometimes severe pain irradiating from the abdominal mass. The patient had two pregnancies in the past, the second of which by caesarean section about 5 years earlier. The caesarean section scar presented in good condition and the mass was not contiguous to the Pfannenstiel's laparotomy scar, located on the left paramedian epigastric region, a few centimetre above the scar (see Figure 1), rounded, and about $5 \mathrm{~cm}$ of diameter, of hard consistence, fixed and adherent to the deep abdominal wall structures. The remainder of the abdominal and gynaecological examinations was unremarkable.

Blood sample demonstrated normal values, apart from slightly elevated levels of CA $125(36.5 \mathrm{U} / \mathrm{ml})$ and CA 19.9 (40.3 U/ml). Ultrasound scan and X-ray had negative or aspecific features. Magnetic resonance imaging gave more interesting patterns, showing the localization of the nodule, involving the deep layers of the abdominal wall ( muscles and fascia, see Figure 2), and the distance from the laparotomic scar (Figure 3).

Surgical removal was performed with wide excision of the lesion, removing the previous abdominal transverse scar, then going up to the mass, which had many tracts invading the surrounding tissue and was adherent to the fascia and the "rectus abdominis" muscle, up to the peritoneal layer, so that the removal was difficult and caused a large wall defect.

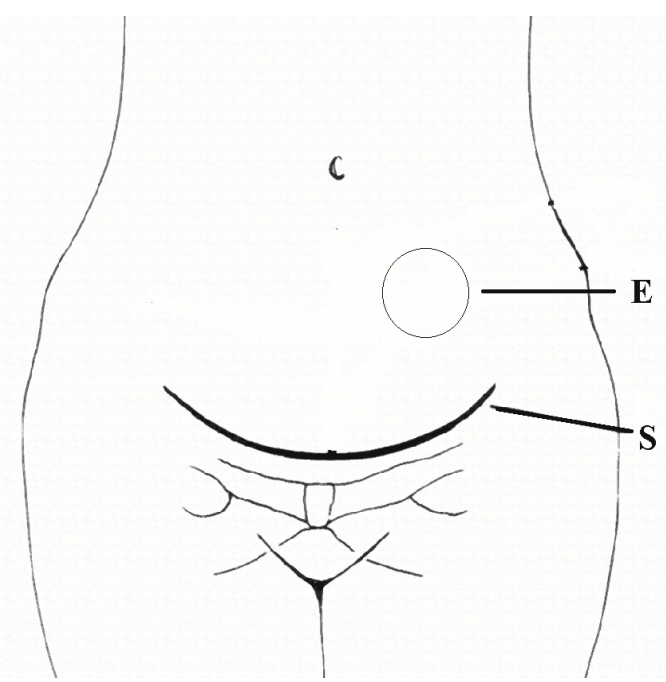

Figure 1. The scheme shows the localization of endometrioma (E) with reference to the Pfannenstiel's laparotomic scar (S) of the previous caesarean section. 


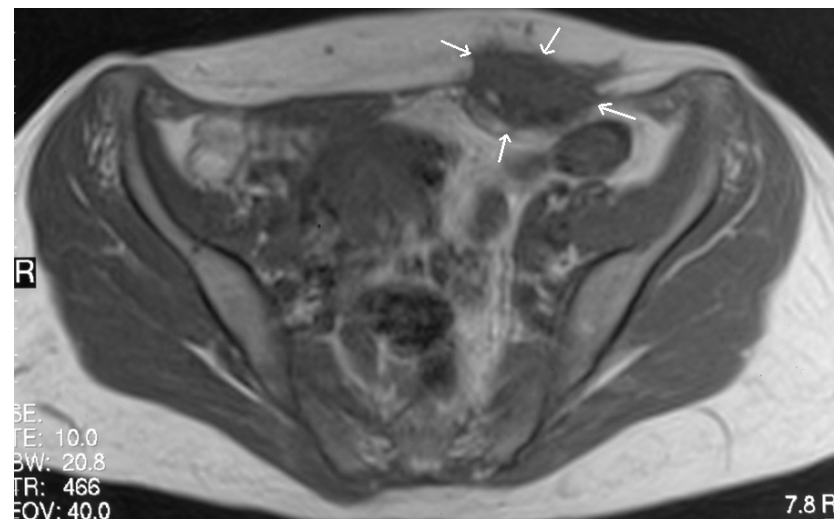

Figure 2. RMI transverse abdominal scan: the deep abdominal wall mass is evidenced (arrows) on the left paramedian side. $\mathrm{E}=$ endometrioma, $\mathrm{S}=$ Pfannenstiel's laparotomic scar.

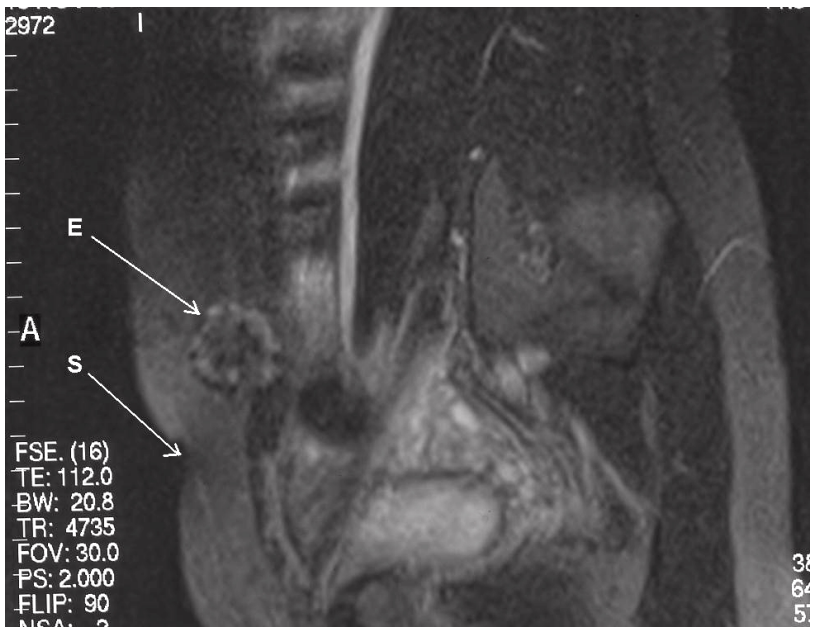

Figure 3. RMI, longitudinal paramedian scan: the distance between the endometrioma (E) and the Pfannenstiel's laparotomic scar (S) of the caesarean section can be seen.

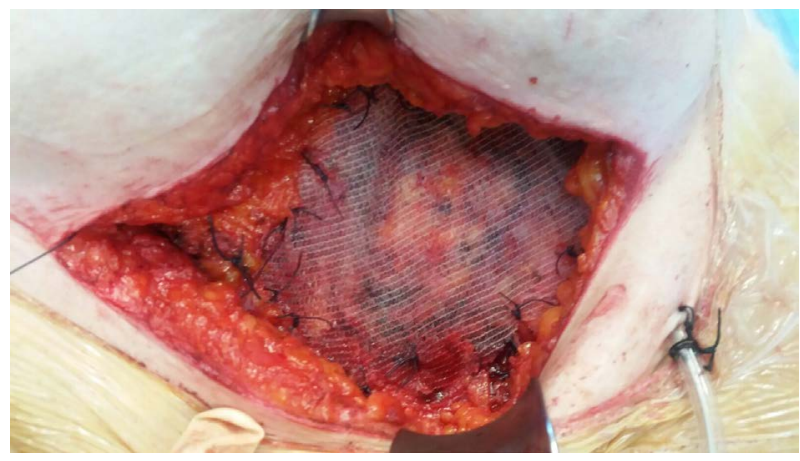

Figure 4. Use of prolene mesh for the abdominal wall defect.

The surgical specimen was then sent for frozen section. After histological confirmation (fibrotic nodule with endometriotic foci) reconstruction of the abdominal wall required prolene mesh grafting for the resulting fascial defect (Figure 4).

To prevent relapse the abdominal wall wound was cleaned thoroughly and ir- 
rigated with saline solution before closure.

Postoperative healing was good and the patient was discharged from hospital 4 days after surgery. At present time, at twelve-month follow-up, the patient does not show any sign of recurrence or late complication.

\section{Discussion}

Endometriosis is a disease affecting as many as $10 \%$ of women of childbearing age [1], and it is defined as the aberrant or heterotopic growth of glands and stroma identical to the lining uterus. It is generally confined to the pelvis, but it can proliferate virtually everywhere, with diffusion of multiple foci or a mass formation (endometrioma).

The abdominal wall is the commonest site of extrapelvic endometrioma, which develops in association with a prior abdominal scar, mainly affecting $0.1 \%$ $0.2 \%$ of women after caesarean section or less frequently after other surgical procedures, such as amniocentesis, laparoscopy, hysterectomy, abdominoplasty, and so on [2] [3] [4] [5]. Women affected generally do not refer prior history of endometriosis. Several theories have been proposed to explain the formation of endometriosis nodes in extrauterine localizations. The two of them that seem to be more plausible are the metaplasia and transport theories [6].

The etiology is thought to be the result of mechanical transplantation of endometrial tissue during surgical procedures, mainly those that imply the opening of uterine cavity. Shed endometrial tissue is viable, highly angiogenic and able to form endometriotic lesions in various model systems [7]. However, spontaneous abdominal wall endometriomas, localized in the recti abdominis, in absence of previous surgery, have been also described [8].

The dimension of abdominal wall endometrioma ranges from micro-endometrioma, from 0.5 to $2 \mathrm{~mm}$, to large endometrioma, with diameter $>3 \mathrm{~cm}$. The latter can be sometimes very large, presenting the typical characteristics of cystic and multiloculated aspect, with signs of internal haemorrhage [3].

Clinically, the onset of symptoms, which are associated with abdominal scar endometrioma, may vary from 6 months up to 19 years after previous surgery [3]-[9].

Symptomatology is constituted essentially by abdominal scar-related mass grow and pain, radiating from the scar, not always severe, or necessarily exacerbating during menstruations [9]. Although abdominal wall endometriosis has typical signs, general surgeons often misdiagnose it due to its rarity [10]. The diagnosis is often difficult, frequently made after excision of the lesion [11]. More recently, accuracy of new generation US technology allows the expert operator to make a diagnosis during the first level echography, with an accurate pre-surgical evaluation. Moreover a high-resolution ultrasound is a simple, inexpensive and safe method and is sufficient for indicating surgery. Furthermore, the use of intraoperative ultrasound allows adequate margins of excision [12].

Fine needle aspiration biopsy (FNAB) has been proposed, for accurate preo- 
perative diagnosis, provided that the difficult cytopathologic interpretation is made on both components: epithelial consisting of flat sheets of polygonal cells with round nuclei and scant cytoplasm, and stromal with clusters of fusiform cells [13]. FNAB may be also helpful in establishing differential diagnosis between clear cell adenocarcinoma and abdominal wall masses [14].

Magnetic resonance imaging (MRI), thanks to its very high spatial resolution, enables very small lesions to be detected, can distinguish the haemorrhagic signal of endometriotic lesions, and performs better than the CT scan in detecting the limits between muscles and abdominal subcutaneous tissues [11]. Malignant or benign tumors of abdominal wall and incisional hernias should be kept in mind for diagnosis of endometrioma. Imaging methods like Doppler US, computed tomography and magnetic resonance imaging should be used for differential diagnosis. Definitive diagnosis can only be made histopathologically [15].

Early diagnosis may strongly influence invasivity and treatment radicality, as in the reported case of scar endometriosis following cesarean section, which was being treated as stitch granuloma for long time. Medical treatment was not helpful. The patient required wide surgical excision of the lesion. Now the patient is under regular follow up, because there is chance of recurrence [16].

Scar endometrioma must be dissected free from the surrounding tissue and excised with clear margins [2]. It is also important to take care against intraoperative auto-inoculation of endometrial tissue in order to prevent recurrences [15].

A procedure of rectus abdominis muscle endometriosis excised under ultrasound guidance has been reported: intraoperative localization was performed through ultrasonography and ultrasound of the abdominal wall showed two hypoechogenic nodules in the context of the right rectus abdominis muscle and a fine-needle aspiration, performed under ultrasound guidance, and confirmed the diagnosis of endometriosis. Then patient underwent surgical excision of the lesions [12].

The wide excision is the treatment of choice for abdominal wall endometrioma as well as for recurrent lesions [17]. Due to the invasion and adherence to the soft tissue, often reconstruction of the abdominal wall is required, after the wide excision of the mass, using polytetrafluoroethylene (Teflon) patch or polypropylene (Prolene) mesh grafting [4].

Prevention of scar endometrioma during caesarean section has been proposed by means of the accurate cleaning of the surgical wound and the irrigation with high-jet saline solution before closure [18].

Despite the rarity of malignant transformation of endometriosis, it should be borne in mind when endometrioma of the abdominal wall is suspected, because an oncological resection is then required [19]. Clear cell carcinoma was the most common histology, followed by endometrioid carcinoma. The rare cases described in literature show that endometriosis-associated abdominal wall cancer may be aggressive and it shows poor prognosis. Death was described in $44 \%$ of 
women within a few months of diagnosis [20] [21] [22].

Moreover, the rare event of malignant transformation of an endometrial implant should be considered in postmenopausal age, the laparotomy being performed many years earlier, while the mean age of patients presenting abdominal wall endometrioma is about 30 years. Intraoperative histological confirmation by means of frozen section seems to be an acceptable prudential procedure in these cases. Differential diagnosis is needed to exclude a desmoid tumor of the abdominal wall, arose on a scar of cesarean section [6]. From a clinical point of view, in the desmoid tumor the pain is not related to the menstrual cycle, although it is important to note that in the abdominal wall endometrioma the cyclic recurrence of pain during menstruation is clearly reported only in $20 \%$ of cases [23].

\section{Conclusions}

In our reported case, the unusual presentation of a large, deep endometrioma of the abdominal wall, in a 36-year old woman, 5 years after a caesarean section, localized some centimetres above the laparotomic scar, rather than being contiguous or in continuity with it, could be explained considering the surgical technique of the Pfannenstiel's laparotomic incision. During dissection between fascia and "recti abdominis" muscles to the top, to allow longitudinal opening of the abdominal cavity, a large space is created, where endometrial tissue can be transported and implanted by surgical manipulation.

When endometrioma is located so distant from the abdominal scar, the differential diagnosis may be more difficult (hernia, soft tissue tumor, abscess, metastatic malignancy). RMI can help differentiating many of these lesions, and histological confirmation should be obtained intraoperatively, by frozen section, to allow an oncological resection if required.

The procedure of cleaning and washing laparotomic wound after caesarean section to prevent endometrial implants is neither frequently performed in our hospitals, nor taught to trainees. Perhaps this problem should be stressed and this preventive practice should be recommended to avoid pain, anxiety and morbidity linked to this late postoperative complication.

\section{References}

[1] Viganò, P., Parazzini, F., Somigliana, E., et al. (2004) Endometriosis: Epidemiology and Aetiological Factors. Best Practice \& Research: Clinical Obstetrics \& Gynaecology, 18, 177-200.

[2] Khamechian, T., Alizargar, J. and Mazoochi, T. (2014) 5-Year Data Analysis of Patients Following Abdominal Wall Endometrioma Surgery. BMC Women's Health, 5,151 .

[3] Bumpers, H.L., Butler, K.L. and Best, I.M. (2002) Endometrioma of the Abdominal Wall. American Journal of Obstetrics \& Gynecology, 187, 1709-1710. https://doi.org/10.1067/mob.2002.121868

[4] Blanco, R.G., Parithivel, V.S., Shah, A.K., Gumbs, M.A., Schein, M. and Gerst, P.H. (2003) Abdominal Wall Endometriomas. The American Journal of Surgery, 185, 596-598. 
[5] Hughes, M.L., Bartholomew, D. and Paluzzi, M. (1997) Abdominal Wall Endometriosis after Amnio-Centesis: A Case Report. The Journal of Reproductive Medicine, 42, 597-599.

[6] Vellido-Cotelo, R., Mu-oz-González, J.L., Oliver-Pérez, M.R., et al. (2015) Endometriosis Node in Gynaecologic Scars: A Study of 17 Patients and the Diagnostic Considerations in Clinical Experience in Tertiary Care Center. BMC Women's Health, 15, 13. https://doi.org/10.1186/s12905-015-0170-9

[7] Nap, A.W., Groothuis, P.G., Demir, A.Y., et al. (2004) Pathogenesis of Endometriosis. Best Practice \& Research: Clinical Obstetrics \& Gynaecology, 18, 233-244.

[8] Ideyi, S.C., Schein, M., Niazi, M. and Gerst, P.H. (2003) Spontaneous Endometriosis of the Abdominal Wall. Digestive Surgery, 20, 246-248.

https://doi.org/10.1159/000070392

[9] Patterson, G.K. and Winburn, G.B. (1999) Abdominal Wall Endometriomas: Report of Eight Cases. The American Surgeon, 65, 36-39.

[10] Oh, E.M., Lee, W.S., Kang, J.M., et al. (2014) A Surgeon's Perspective of Abdominal Wall Endome-Triosis at a Caesarean Section Incision: Nine Cases in a Single Institution. Surgery Research and Practice, 2014, Article ID: 765372.

[11] Balleyguier, C., Chapron, C., Chopin, N., Helenon, O. and Menu, Y. (2003) Abdominal Wall and Surgical Scar Endometriosis; Results of Magnetic Resonance Imaging. Gynecologic and Obstetric Investigation, 55, 220-224.

https://doi.org/10.1159/000072078

[12] Coccia, M.E., Rizzello, F., Nannini, S., et al. (2015) Ultrasound-Guided Excision of Rectus Abdominis Muscle Endometriosis. Journal of Obstetrics and Gynaecology Research, 41, 149-152. https://doi.org/10.1111/jog.12502

[13] Simsir, A., Thorner, K., Waisman, J. and Cangiarella, J. (2001) Endometriosis in Abdominal Scars: A Report of Three Cases Diagnosed by Fine-Needle Aspiration Biopsy. The American Surgeon, 67, 984-986.

[14] Heller, D.S., Houck, K., Lee, E.S. and Granick, M.S. (2014) Clear Cell Adenocarcinoma of the Abdominal Wall: A Case Report. The Journal of Reproductive Medicine, 59, 330-332.

[15] Cöl, C. and Yilmaz, E.E. (2014) Cesarean Scar Endometrioma: Case Series. World Journal of Clinical Cases, 2, 133-136. https://doi.org/10.12998/wjcc.v2.i5.133

[16] Saha, K., Shahida, S.M., Mostafa, G. and Ahmed, M. (2014) A Case of Abdominal Wall Scar Endometriosis. Mymensingh Medical Journal, 23, 389-391.

[17] Bachir, J.S. and Bachir, N.M. (2002) Scar Endometrioma: Awareness and Prevention. $W M J, 1001,46-49$.

[18] Wasfie, T., Gomez, E., Seon, S. and Zado, B. (2002) Abdominal Wall Endometrioma after Cesarean Section: A Preventable Complication. International Surgery, 87, 175 177.

[19] Matter, M., Schneider, N. and McKee, T. (2003) Cystoadenocarcinoma of the Abdominal Wall Following Caesarean Section: Case Report and Review of the Literature. Gynecologic Oncology, 91, 438-443.

[20] Taburiaux, L., Pluchino, N., Petignat, P. and Wenger, J.M. (2015) EndometriosisAssociated Abdominal Wall Cancer: A Poor Prognosis? International Journal of Gynecological Cancer, 25, 1633-1638. https://doi.org/10.1097/IGC.0000000000000556

[21] Ruiz, M.P., Wallace, D.L. and Connell, M.T. (2015) Transformation of Abdominal Wall Endometriosis to Clear Cell Carcinoma. Case Reports in Obstetrics and Gy- 
necology, 2015, Article ID: 123740.

[22] Sosa-Durán, E.E., Aboharp-Hasan, Z., Mendoza-Morales, R.C., et al. (2016) Clear Cell Adenocarcinoma Arising from Abdominal Wall Endometriosis. Cirugía y Cirujanos, 84, 245-249.

[23] Chatziparadeisi, A., Daniilidis, A., Diavatis, S., et al. (2014) Abdominal Wall Endometriosis after a Caesarian Section-An Interesting Case Report. Clinical and Experimental Obstetrics and Gynecology, 4, 360-361.

Submit or recommend next manuscript to SCIRP and we will provide best service for you:

Accepting pre-submission inquiries through Email, Facebook, LinkedIn, Twitter, etc. A wide selection of journals (inclusive of 9 subjects, more than 200 journals)

Providing 24-hour high-quality service

User-friendly online submission system

Fair and swift peer-review system

Efficient typesetting and proofreading procedure

Display of the result of downloads and visits, as well as the number of cited articles

Maximum dissemination of your research work

Submit your manuscript at: http://papersubmission.scirp.org/

Or contact ojog@scirp.org 